\title{
Doxapram Hydrochloride
}

National Cancer Institute

\section{Source}

National Cancer Institute. Doxapram Hydrochloride. NCI Thesaurus. Code C47500.

A peripheral and central respiratory stimulant with a brief duration of action. Doxapram

hydrochloride stimulates respiration by an action on chemoreceptors in the carotid arteries and, at increased dosage, stimulates central respiratory centers in the medulla as well as other parts of the brain and spinal cord. This results in an increased tidal volume and a slightly increased respiratory rate. Doxapram hydrochloride may also improve cardiac output probably due to an increased release of catecholamines. This respiratory stimulant is used in postanesthesia respiratory depression. 